\title{
PERSEPSI PENGEMBANGAN WILAYAH KAWASAN WISATA SITU BABAKAN DI PROVINSI DKI JAKARTA
}

\author{
Development Perception of \\ Tourist Area of Situ Babakan \\ In The Province of DKI Jakarta
}

\author{
Jefny B. Markus Rawung ${ }^{1}$ dan Rita Indrasti ${ }^{2}$ \\ ${ }^{1}$ Balai Pengkajian Teknologi Pertanian (BPTP) Sulawesi Utara \\ Email: jbmarkusrawung2000@yahoo.com
}

${ }^{2}$ Balai Besar Pengkajiandan Pengembangan Teknologi Pertanian (BBP2TP) Bogor

Email: ritaindrasti@yahoo.com

\begin{abstract}
Situ Babakan is one of the tourist areas in the Jakarta area, precisely in South Jakarta. The existence of the development of this tour must be the community feel the excitement, but the perception of this development will always be different. The development of tourist areas will have an impact on the surrounding environment. The study took 50 respondents, the parameters include gender, age, occupation and respondents' perceptions of the development of the tourist area. Interviews were conducted using a questionnaire. Analysis is done descriptively. The study was conducted in 2017 around the Situ Babakan area. The context of this study is conducive to developing tourist areas. It is hoped that local communities will also have an impact on increasing income, preserving Betawi culture, and the Regional Government has also supported the activity. Perceptions about tourism development have a real relationship with local communities in particular.
\end{abstract}

Keywords: Situ Babakan, tourism area, perception, local communities

\section{ABSTRAK}

Situ Babakan adalah salah satu daerah wisata yang berada di daerah Jakarta, tepatnya di Jakarta Selatan. Adanya pengembangan wisata ini pastilah masyarakat merasakan kegembiraan, namun persepsi tentang pengembangan ini akan selalu berbeda. Pengembangan wilayah wisata akan berdampak terhadap lingkungan sekitar. Penelitian tersebut mengambil 50 responden, parameternya antara lain yaitu jenis kelamin, umur, pekerjaan dan persepsi responden terhadap pengembangan wilayah kawasan wisata. Wawancara dilakukan dengan menggunakan kuiseoner. Analisis dilakukan secara deskriptif. Kajian dilakukan pada tahun 2017 di sekitar daerah Situ Babakan. Konteks kajian ini termasuk kondusif dalam pengembangan wilayah wisata. Diharapkan masyarakat lokal berdampak juga untuk menambah pendapatan, melestarikan budaya Betawi, Pemda pun ikut mendukung kegiatan tersebut. Persepsi tentang pengembangan wisata memiliki hubungan yang nyata dengan masyarakat lokal khususnya.

Kata kunci: Situ Babakan, kawasanwisata, persepsi, masyarakatlokal.

\section{PENDAHULUAN}

Suatu daerah dapat menjadi tujuan wisata jika daerah tersebut bisa dikembangkan menjadi daerah atraksi wisata. Sesuatu atraksi wisata yang menarik adalah yang dapat mengundang para wisatawan atau pengunjung untuk berkunjung serta merasakan kenyamanan dan kepuasan. Mutu atau kualitas objek wisata tidak selalu dinilai dari fasilitas sarana dan prasarana saja namun juga pelayanan, aksesibilitas yang mendukungnya.

Seiring dengan hal tersebut maka DKI Jakarta sebagai kota metropolitan mempunya peluang yang sangat besar untuk mengembangkan wisata perkotaan.Pengembangan Situ Babakan sebagai salah satu daerah wisata nampaknyapilihan yang sangat tepat. Namun jika pengelolaan Situ Babakan tidak baik dan tidak sesuai daya dukung 
maka akan menimbulkan dampak negatif yang dapat menimbulkan kerusakan sumberdaya perairan di Situ Babakan. Hasil penelitian Arief (1999), menyatakan bahwa situ, danau dan waduk di Indonesia pemanfaatannya selain untuk keperluan pengairan, pertanian dan juga pembangkit tenaga listrik maka bisa juga dimanfaatkan sebagai tempat wisata. Namun kawasan tersebut harus dijaga kelestariannya agar tetap bisa berkelanjutan. Lukman (1999) menyatakan bahwa agar situ, danau atau waduk lebih menarik maka perlu dipelihara ikan di dalamnya. Misal di Danau Semayang, Kalimantan Timur ada bebrapa jenis ikan yang hidup dan mempunyai nilai ekonomis.

Sejalan dengan upaya Pemerintah Daerah (PEMDA) DKI Jakarta untuk meningkatkan peranan sektor wisata di DKI Jakarta antara lain, melalui (1) pemantapan dan pengembangan potensi sumberdaya alam wisata yang dimiliki di DKI Jakarta, (2) DKI Jakarta diharapkan sebagai contoh teladan dalam menciptakan wisata baru, (3) mengembangkan DKI Jakarta sebagai tempat tujuan wisata, (4) meneladani upaya pelestarian lingkungan hidup yang berkelanjutan dan budaya yang seiring dengan sasaran atau tujuan utama pembangunan, dan (5) menjadikan DKI Jakarta sebagai tujuan untuk perjalanan wisata yang lestari dan berkelanjutan.Didukung oleh pernyataan Jalaluddin (2002) bahwa persepsi merupakan pengalaman tentang wisata, obyek atau hubungan yang diperoleh dengan dapat menyimpulkan informasi yang digali dan dapat menarik kesimpulan dari persepsi tersebut. Dalam hal ini adalah bagaimana pengunjung mempunyai persepsi tentang pengembangan kawasan wiasata
Situ Babakan tersebut? Penelitian ini bertujuan untuk mengetahui sejauh mana persepsi pengunjung tentang pengembangan kawasan wisata Situ Babakan.

\section{METODE PENELITIAN}

Penelitian dilaksanakan pada bulan Agustus sampai dengan Desember 2017 di wilayah wisata Situ Babakan. Data dianalisis secara deskriptif dan juga non 162egative162c.Data yang diperlukan adalah data primer dan sekunder. Data sekunder diambil dari instansi terkait umuk mendukung data lokasi penelitian.. Metode 162egati adalah pengamatan yang dilakukan untuk memperoleh fakta yang ada karena untuk mencari bukti dari daerah tertentu atau suatu kelompok. Sampel dalam penelitian ini adalah50 pengunjung yang datang ke lokasi wisata Situ Babakan. Asgari (1992) menyatakan bahwa penilaian dan keputusan dilakukan pada saat tahap intepretasi seseorang dan juga pengaruh pengalamannya.

\section{HASIL DAN PEMBAHASAN}

Wisata Situ Babakan terletak di Kelurahan Srengseng Sawah, Kecamatan Jagakarsa, Jakarta Selatan.Air Situ Babakan berasal dari sungai Ciliwung, luas Situ Babakan adalah $32 \mathrm{Ha}$. Di Kelurahan Srengseng Sawah merupakan daerah perkampungan Betawi. Budaya Betawi dikenal sebagai masyarakatnya yang ramah dan sangat menghargai budaya goyong royong. Topografi di wilayah ini cenderung agak bergelombang dengan ketinggian $25 \mathrm{mdpl}$, curah hujan tahunan berkisar antara $2000-2500 \mathrm{~mm}$.

Tabel 1. Pendapat pengunjung tentang Situ Babakan

\begin{tabular}{|c|c|c|}
\hline Parameter & Kategori & Jumlah (\%) \\
\hline \multirow[t]{3}{*}{ Perubahan lingkungan SB } & Lebih banyak positif & 36,6 \\
\hline & Lebih banyak 162egative & 48,8 \\
\hline & Sama saja & 14,6 \\
\hline \multirow[t]{3}{*}{ Perubahan sosial } & Lebih banyak positif & 51,3 \\
\hline & Lebih banyak 162egative & 2,4 \\
\hline & Sama saja & 46,3 \\
\hline \multirow{3}{*}{$\begin{array}{l}\text { Pentıng tidaknya } \\
\text { dipertahankan }\end{array}$} & Sangat penting & 75 \\
\hline & Penting & 25 \\
\hline & Tidak penting & 0 \\
\hline
\end{tabular}

Data olah survey tahun 2017

Pada tabel 1 dijelaskan bahwa perubahan lingkungan Situ Babakan responden cenderung menyatakan negatif $(48,8 \%)$ hal ini dikarenakan kondisi Situ Babakan sudah mulai dangkal dan kotor dibandingkan dengan kondisi beberapa tahun yang lalu. Untuk responden yang menyatakan lebih banyak positif $(36,6 \%)$ kemungkinan responden tersebut belum pernah ke Situ Babakan sedangkan responden yang menyatakan sama saja $(14,6)$ responden tersebut tidak peduli dengan perubahan lingkungan. Sikap masyarakat lokal sangat berpengaruh terhadap keberadaan Situ Babakan karena bisa menambah pendapatan mereka. Hal ini didukung dengan pernyataan Sarlito (1999) bahwa ada dua ciri sikap seseorang, (1) adanya obyek tertentu, misalnya perilaku, manusia, situasi), (2) adanya penilaian setuju atau tidak, mau atau tidak mau bahkan juga suka ataupun tidak suka. Data perubahan sosial mengarah lebih positif $(51,3 \%)$ karena kesadaran akan lingkungan tercermin juga dari perubahan sosial dari masyarakat lokal ataupun pengunjung. Keberadaan Situ Babakan seharusnya memang dipertahankan karena sangat penting untuk pelestarian dan keberlanjutan lingkungan. Ardika (1999) menyatakan bahwa kawasan Situ Babakan 
jika sebagai obyek wisata maka daya tarik wisata sangat tergantung juga pada kualitas lingkungan perairan.

Tabel 2. Karakteristik pengunjung Situ Babakan

\begin{tabular}{lcc}
\hline \multicolumn{1}{c}{ Karakteristik pengunjung } & Jumlah & Jumlah total (\%) \\
\hline Pekerjaan pokok & 16 & $16 \%$ \\
PNS & 41 & $41 \%$ \\
Swasta & 3 & $3 \%$ \\
Petani & 26 & $26 \%$ \\
Pedagang/pengusaha & 12 & $12 \%$ \\
TNI/Polri & 2 & $2 \%$ \\
Lainnya & & \\
Umur & 13 & $13 \%$ \\
$<17$ tahun & 42 & $42 \%$ \\
$26-35$ tahun & 22 & $22 \%$ \\
$36-50$ tahun & 23 & $23 \%$ \\
$>50$ tahun & & \\
Pendidikan & 7 & $7 \%$ \\
SD & 25 & $25 \%$ \\
SMP & 40 & $40 \%$ \\
SMA & 28 & $28 \%$ \\
Perguruan Tinggi & & \\
Jarak asal pengunjung & 43 & $43 \%$ \\
$1-6$ km & 51 & $51 \%$ \\
$7-15$ km & 6 & $6 \%$ \\
$>20$ km & & $64 \%$ \\
Status pengunjung & 64 & $36 \%$ \\
Sudah berkeluarga & 36 & \\
Belum berkeluarga & & \\
\hline Data olah survey tahun 2017 & &
\end{tabular}

Data olah survey tahun 2017

Sedangkan pada tabel 2 dibahas tentang karakteristik pengunjung (pekerjaan pokok, umur, pendidikan, jarak asal pengunjung dan status pengunjung). Pekerjaan pokok sebagian besar dari pengunjung adalah swasta, diduga penduduk DKI Jakarta yang bekerja di swasta lebih memanfaatkan waktunya untuk berwisata hal ini dipengaruhi oleh kesibukannya yang membuat jenuh menjadikan mereka menyempatkan untuk melakukan wisata. Usia yang paling banyak berkunjung adalah usia sekitar 26 sampai 35 tahun $(42 \%)$, usia tersebut dianggap usia yang masih sangat memerlukan refreshing untuk wisata meskipun usia yang lain juga masih membutuhkannya. Tingkat pendidikan pengunjung sangatlah beragam, hasil survei menunjukkan bahwa pendidikan SMA (40\%) yang banyak berkunjung di Situ Babakan kemudian disusul oleh pendidikan yang lain. Pendidikan SMA dikatagorikan adalah remaja. Wisata Situ Tabel 3. Pengembangan Kawasan Wisata Situ Babakan (\%)

\begin{tabular}{llll}
\hline \multicolumn{1}{c}{$\begin{array}{c}\text { Program } \\
\begin{array}{l}\text { Pengembangan } \\
\text { Kawasan Wisata }\end{array}\end{array}$} & Setuju & Ragu-ragu & Tidak setuju \\
\hline $\begin{array}{l}\text { Pembangunan jalan } \\
\text { menuju lokasi wisata }\end{array}$ & 74 & 23 & 3 \\
$\begin{array}{l}\text { Adanya promosi yang } \\
\text { kontinyu }\end{array}$ & 75 & 20 & 5 \\
$\begin{array}{l}\text { Perlunya arena bermain } \\
\text { Perluasan arena parkir }\end{array}$ & 65 & 25 & 10 \\
Pelestarian budaya & 68 & 28 & 4 \\
\hline
\end{tabular}

Babakan dominan dikunjungi oleh remaja hal ini disebabkan kalangan remaja ingin refreshing dengan biaya yang relatif murah.

Sebanyak 51\% pengunjung jarak asal ke lokasi sekitar $7-15 \mathrm{~km}$, peluang pengunjung meskipun agak jauh namun wisata Situ Babakan sangat diminati, kemungkinan penduduk DKI Jakarta haus akan wisata yang relatif murah. Pengunjung yang domisilinya dekatpun sangat berminat untuk datang ke wisata Situ babakan (43\%). Sittu Babakanpun dianggap tempat yang cukup representatif bagi pengunjung yang berjarak dekat maupun jauh. Status berkeluarga sebanyak $64 \%$ yang telah banyak berwisata mengunjungi Situ Babakan dibandingkan yang belum berkeluarga (36\%). Status berkeluarga sangat membutuhkan wisata dan merekapun akan mengajak keluarga maka diduga Situ Babakan menjadi pilihan mereka untuk melakukan wisata.

Data olah survey tahun 2017 
Pengembangan kawasan wisata yang potensi harus didukung oleh beberapa hal, penelitian Sulistyantara (1990) menyatakan bahwa wisata di perkotaan agar dapat memberikan manfaat apabila, (1) wisata tersebut harus membuat vegetasi yang dapat memberikan manfaat dalam perbaikan kualitas iklim mikro, (2) pengembangan kawasan dapat menjaga kelestarian lingkungan dan memperbaiki iklim mikro dan dapat mengurangi erosi, (3) wisata juga dapat menjadi sumber penghasilan bagi perorangan ataupun kelompok.

Agar wisata tersebut dapat lebih terjangkau maka akses menuju ke lokasi harus diperhatikan. Akses yang mudah terjangkau dan jalan yang bagus sangat mendukung kegiatan wisata tersebut apalagi biaya untuk wisata terjangkau harganya bagi para pengunjung. Sejalan dengan Silver (1996) mengemukakan bahwa aset atau modal yang mempunyai potensi di daerah perkotaan dapat dimasukkan dalam kategori program wisata, antara lain tapak warisan budaya, taman ataupun pemukiman etnis.

Arena bermain dan perluasan parkir sangat melengkapi kenyamanan wisata. Arena bermain ditujukan untuk anak-anak agar tidak bosan hanya memandang Situ saja dan bermain adalah selingan buat anak-anak. Perluasan parkirpun harus diperhatikan karena merupakan salah satu kenyamanan dan keamanan juga.

Pelestarian budaya sangatlah perlu. Pengembangan wisata Situ Babakan berarti juga pengembangan perkampungan budaya Betawi, masyarakat Betawi dikenal sebagai masyarakat yang ramah dan sangat suka kegiatan gotong royong antar warga. Surata (1993) menyatakan bahwa pengaruh adanya faktor eksternal adalah pengaruh kelompok dan perbedaan latar belakang budaya. Budaya Betawi pasti sangat berbeda dengan budaya-budaya lainnya. Hal inipun didukung oleh hasil penelitian Supriadi (1999).

\section{SIMPULAN}

Situ Babakan mempunyai potensi untuk dikembangkan sebagai wisata. Persepsi masyarakat pengunjung sangat mendukung keberadaan wisata Situ Babakan. Masyarakat lokalpun juga mendukung dikarenakan terkait akan penambahan pemasukkan ekonomi mereka. Masyarakat lokal bisa menjual cenderamata, khas makanan betawi ataupun minuman bir pletok. Dengan demikian masyarakat lokal bisa lebih makmur.

\section{DAFTAR PUSTAKA}

Ardika, 1999. Pariwisata Berkelanjutan Menurut Perspektif Orang Bali. Seminar International Paiwisata Berkelanjutan. Kerjasama Pusat Penelitian Kebudayaan dan Pariwisata, Universitas Udayana. Denpasar. Bali. Service. East Texas State University.

Arief, 1999. Danau dan Waduk Ditinjau dari Aspek Pelestarian dan Pemanfaatan. Semiloka Nasional Pengelolaan dan Pemanfaatan Danau dan Waduk.

Asngari, 1992. Perception of District Extension Director and Country Extension Agent Chairman Regarding the Roles and Function of Texas Agricultural Extension.

Jalaluddin, 2002. Psikologi Komunikasi. PT. Remaja Rosdakarya. Bandung.

Lukman, 1999. Karakteristik dan Strategi Pemanfaatan Sumberdaya Danau. Semiloka Nasional Pengelolaan dan Pemanfaatan Danau dan Waduk. Bogor.

Sarlito, 1999. Psikologi Sosial. Individu dan Teori-Teori Psikologi Sosial. Balai Pustaka. Jakarta.

Silver, 1996. Ekowisata Berbasis Kota di Indonesia. Prosiding Pelatihan dan Lokakarya Perencanaan Pariwisata Berkelanjutan. ITB. Bandung.

Supriadi, 1999. Pengaruh Bentuk Penyajian Pesan Video dan Penggunaan Ilustrasi Grafis dalam Medium pada Peningkatan Pengetahuan Penyuluh Lapangan. Sumatera Selatan. Palembang.

Sulistyantara, 1990. Pengembangan Wisata Agro di Perkotaan. Prosiding Simposium dan Seminar Nasional Hortikultura Indonesia. Bogor.

Surata, 1993. Persepsi Seniman Lukis Tradisional Bali Terhadap Konservasi Burung. Denpasar. 